\title{
Characterization of water management in metal foam flow-field based polymer electrolyte fuel cells using in-operando neutron radiography
}

Y. Wu, ${ }^{a}$ J. I. S. Cho,,${ }^{a, b}$ M. Whiteley, ${ }^{a, c}$ L. Rasha, ${ }^{a}$ T. P. Neville, ${ }^{a}$ R. Ziesche, ${ }^{a}$ R. Xu,${ }^{a}$ R. Owen, ${ }^{a}$ N. Kulkarni, ${ }^{a}$ J. Hack, ${ }^{a}$ M. Maier, ${ }^{a}$ N. Kardjilov, ${ }^{d}$ H. Markötter, ${ }^{d}$ I. Manke, ${ }^{d}$ F. R. Wang, ${ }^{a}$ P. R. Shearing, ${ }^{\mathrm{a}, \mathrm{c}}$ D. J. L. Brett ${ }^{\mathrm{a}, \mathrm{c} *}$

${ }^{a}$ Electrochemical Innovation Lab (EIL), Department of Chemical Engineering, University College London, London WC1E 7JE, United Kingdom.

${ }^{b}$ EPSRC "Frontier Engineering" Centre for Nature Inspired Engineering \& Department of Chemical Engineering, University College London, London WC1E 7JE, United Kingdom.

${ }^{\mathrm{c} A d v a n c e d}$ Propulsion Lab (APL), University College London, London WC1E 7JE, United Kingdom

${ }^{\mathrm{d}}$ Helmholtz-Zentrum Berlin (HZB), Hahn-Meitner-Platz 1, 14109 Berlin, Germany

Email: d.brett@ucl.ac.uk (D. J. L. Brett)

\begin{abstract}
Metal foam flow-fields have shown great potential in improving the uniformity of reactant distribution in polymer electrolyte fuel cells (PEFCs) by eliminating the 'land/channel' geometry of conventional designs. However, a detailed understanding of the water management in operational metal foam flow-field based PEFCs is limited. This study aims to provide the first clear evidence of how and where water is generated, accumulated and removed in the metal foam flow-field based PEFCs using in-operando neutron radiography, and correlate the water 'maps' with electrochemical performance and durability. Results show that the metal foam flow-field based PEFC has greater tolerance to dehydration at $1000 \mathrm{~mA} \mathrm{~cm} \mathrm{~cm}^{-2}$, exhibiting a $\sim 50 \%$ increase in voltage, $\sim 127 \%$ increase in total water mass and $\sim 38 \%$ decrease in high frequency resistance (HFR) than serpentine flow-field design. Additionally, the metal foam flow-field promotes more uniform water distribution where the standard deviation of the liquid water thickness distribution across the entire cell active area is almost half that of the serpentine. These superior characteristics of metal foam flow-field result in greater than twice the maximum power density over serpentine flow-field. Optimizing fuel cell operating condition and foam microstructure would partly mitigate flooding in the metal foam flow-field based PEFC, which will form the basis of future work.
\end{abstract}

Keywords: Metal foam flow-field; Fuel cell; Water management; Neutron imaging; Water distribution 


\section{Introduction}

Polymer electrolyte fuel cells (PEFCs) are a low carbon technology for a wide range of power applications. They offer the advantages of high efficiency, low operating temperature and zero harmful emission. One of the major hurdles in commercialization of PEFCs is achieving effective water management [1][3].

Flow-fields serve numerous important roles such as reactant supply and product removal which dictate the performance, efficiency and longevity of PEFCs [4]-[6]. Graphite is one of the most commonly used materials for flow-field plates as it provides good corrosion resistance and electrical conductivity. However, graphite based flow-fields are heavy and suffer from expensive machining cost and brittleness [7][6]. Metallic flow-field is a popular alternative to graphite flow-field but the harsh operating environment of the PEFC poses a significant challenge to corrosion protection even with surface coating which often leads to accelerated performance degradation [7]. Numerous flowfield channel designs have been developed with parallel and serpentine being the most commonly used geometries [8], [9]. These typically rely on a network of open flow channels to distribute gaseous reactants and lands for electric conduction to and from the electrodes. Conventional flowfield designs that use channel/land configuration can lead to channel flooding and non-uniform reactant gas distribution [10]-[12][12], which, in turn, can be detrimental to fuel cell performance and longevity [13]-[15]. Metal foam is one of several flow-field designs that have been reported in the literature to circumvent these problems [16]. Metal foam entails several benefits when used as flowfield including being extremely lightweight due to high porosity (the porosity of pristine foam is usually above 90\%) [17]-[19] and allowing for more uniform flow distribution across the active area due to the homogeneous porous structure [20][28]. However, the design rules for optimizing metal foam flow-fields have not been established and not much is known about the water management (formation, accumulation and removal) across the structure.

Modelling has been employed to predict performance, but generally lacks comprehensive experimental validation. A 3-D macroscale two-phase PEFC model was proposed to compare water distribution and cell performance in metal foam and serpentine flow-field designs [29]. Simulation 
predicted improved reactant homogeneity and membrane hydration for metal foam based PEFCs. A volume of fluid (VOF) method was employed with the reconstructed metal foam to study single and two phase flow characteristics [30]. Additionally, the effects of pore property of the metal foam on water distribution in PEFCs were investigated using a 3D two phase model [31]. Results showed that metal foam flow-field design improves reactant homogeneity and membrane hydration under low humidity operating conditions owing to its unique porous structure.

Various experimental methods have been employed to study the internal water management of PEFCs. Optical microscopes offer the ability to identify the dynamics of water inside the metal foam flowfield [32]. X-ray computed tomography (CT) measurement has been employed along with pressure drop analysis to locally resolve the residence time and distribution of dye across the metal foam [33]. In addition to this, a compression testing system has been combined with the X-ray CT to investigate the mechanical behaviour of PEMFCs using metal foam flow-fields [34]. However, most experimental effort have thus far resorted to ex-situ characterization and only few studies report inoperando water management in metal foam flow-field based PEFCs. High-resolution neutron imaging is a powerful technique used to study transport of water across operating PEFCs [35], [36]. Neutrons penetrate deeply through many common metals, and have a high sensitivity to light elements (i.e., water). This trait allows evaluation of the effect of flow-field designs on water dynamics across the entire fuel cell active area [37]-[48].

The objective of this study is to investigate the effect of metal foam flow-field on the water management of operating PEFC. In-operando neutron radiography is conducted, along with Ohmic resistance and transient cell voltage measurement, to evaluate the effect of liquid water formation and transport on the performance of metal foam and serpentine flow-field based PEFCs. This study also compares the degree of uniformity of water distribution across metal foam and serpentine flow-field designs.

\section{Experimental setup}

\subsection{Fuel cell design}


Fig. 1 (a) shows an 'exploded view' of the PEFC with a metal foam flow-field at the cathode. The 25 $\mathrm{cm}^{2}$ MEA was assembled from commercial GDEs with a platinum catalyst loading of $0.4 \mathrm{mg} \mathrm{Pt} \mathrm{cm}{ }^{-2}$ (HyPlat, South Africa) and a GORE-SELECT membrane (thickness: $20 \mu \mathrm{m}$ ). The MEA was hot pressed at $130^{\circ} \mathrm{C}$ for 3 minutes at 400 psi applied pressure (Carver 4122CE, USA) [47]. Tygaflor sheets of $70 \mu \mathrm{m}$ thick were laser-cut to seal the edge of the MEA on either side of the membrane. The same material was used for electrical insulation between the current collector and the end-plates.

(a)
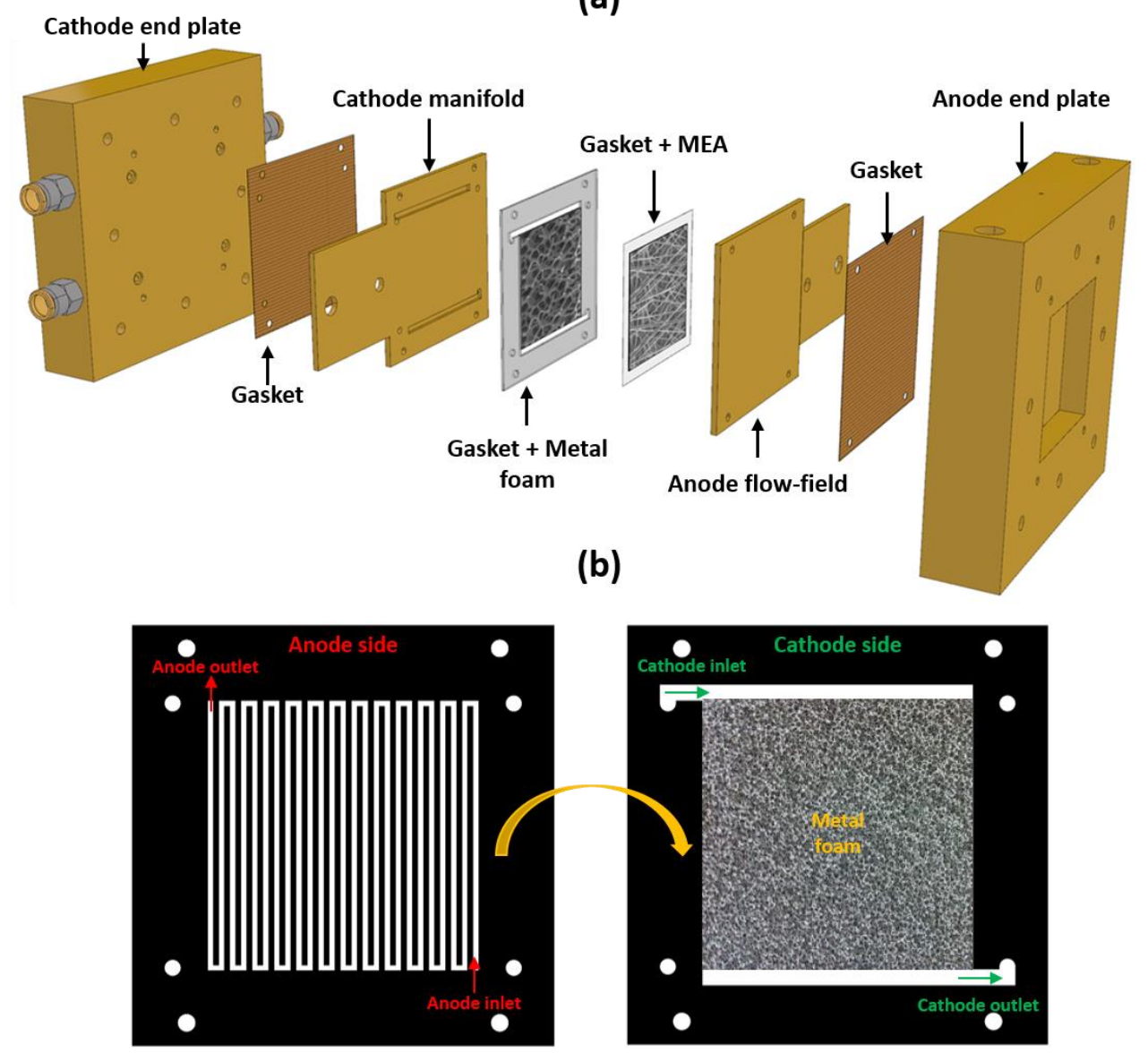

Fig. 1. (a) Exploded view and (b) flow-field design of PEFC.

The single-channel serpentine geometry was used as the anode flow-field (Fig. 1 (b)). The width, land and channel depth were all $1 \mathrm{~mm}$. The aluminium flow-field was electroless coated in gold to prevent corrosion. Nickel foam was coated in graphene via chemical vapour deposition (CVD) for corrosion resistance [49], [50]. The uncompressed graphene-coated nickel foam (Six Carbon Technology, China) is $1.6 \mathrm{~mm}$ thick with a contact angle of $102^{\circ}$ (manufacturer data). It was placed between the MEA and 
a cathode manifold as shown in Fig. 1 (a) and (b). A silicone gasket (thickness: $1 \mathrm{~mm}$ ) was used to ensure good sealing and adequate foam compression. The foam was compressed to $1.0 \mathrm{~mm}$. Scanning electron microscopy (SEM) was employed to display the microstructure of the compressed foam (Fig. 2 (a)). A pixel resolution of $1.587 \mu \mathrm{m}$ was achieved using the lab SEM (Carl Zeiss, USA). A laboratory X-ray CT system, ZEISS Xradia 520 Versa (Carl Zeiss, USA) was used to investigate the microstructure of the compressed metal foam (Fig. 2 (b-d)). A source voltage of $90 \mathrm{kV}$ and a field-ofview of $2.19 \times 2.19 \mathrm{~mm}^{2}$ were used for the sample, giving a voxel size of $1.08 \mu \mathrm{m}$. The reconstructed sample volumes were segmented into solid and pore phase using Avizo V9.0 software (FEI, Bordeaux) package. The porosity of the uncompressed and compressed graphene-coated nickel foam were calculated from the X-ray CT data as $95.8 \%$ and $94.2 \%$, respectively. The performance of the metal foam flow-field based PEFC was evaluated against to a conventional three-channel serpentine flowfield. The width, land and channel depth were all $1 \mathrm{~mm}$.

(a)

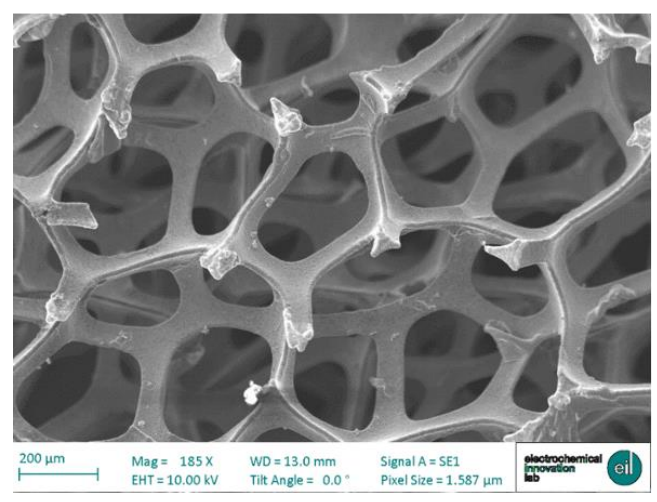

(c)

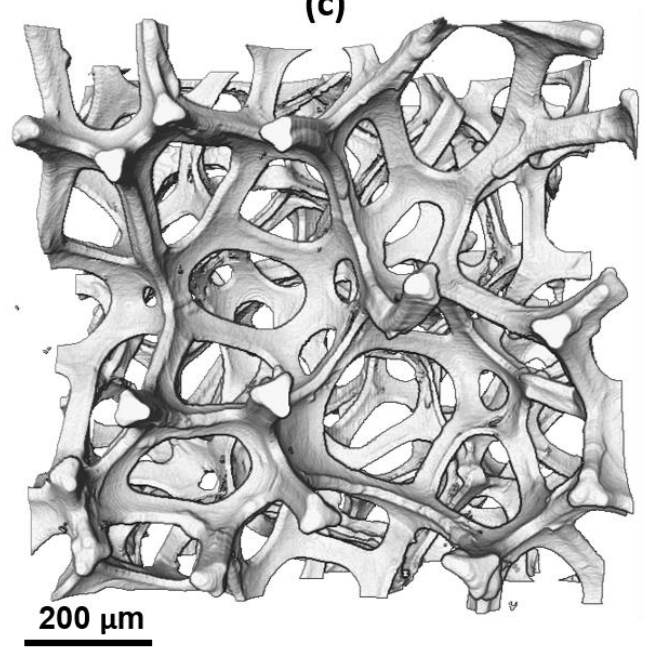

(b)

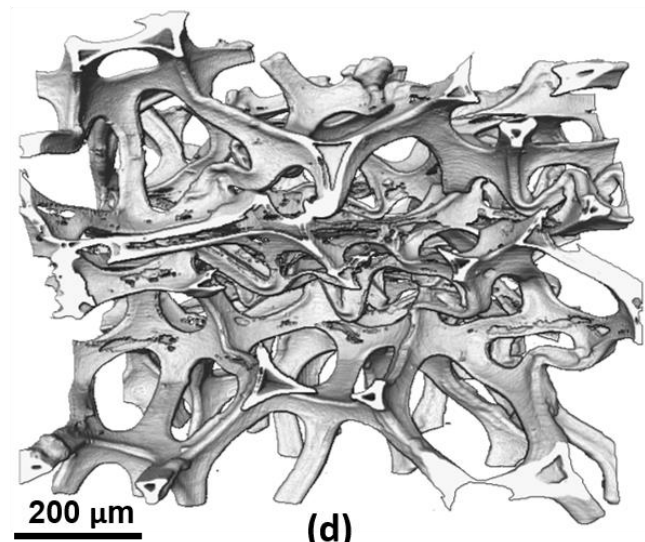

(d)

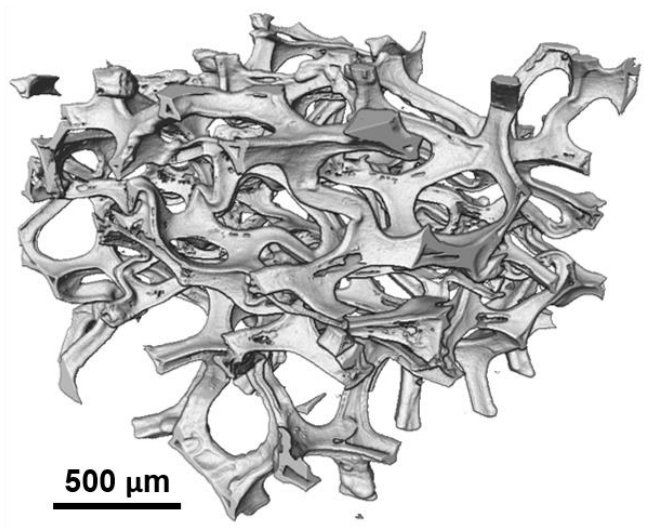


Fig. 2 (a) SEM micrograph of the compressed graphene-coated nickel foam; (b) Side view, (c) Top view and (d) $3 \mathrm{D}$ rendering of the reconstructed microstructure of the compressed metal foam.

\subsection{Fuel cell testing}

In-house fuel cell test rig and control software based on LabVIEW (National Instruments, USA) were used to operate the PEFC. Dry air and high purity hydrogen (99.995\%) were supplied through two digital mass flow controllers (Bronkhorst, UK). The stoichiometric ratio of air and hydrogen were 3 and 1.5 , respectively. The minimum flow rate for both gases was $0.05 \mathrm{~L} \mathrm{~min}^{-1}$. The experimental data were recorded with a data acquisition card (DAQ card, USB 6363, National Instruments, USA). A DC electronic load (PLZ664WA, KIKUSUI) was used to simulate an external load. The high-frequency resistance (HFR) of the PEFCs was recorded separately via a built-in frequency response analyzer in the Scribner 840 advanced fuel cell test system to assess the membrane hydration level. The pressure drop across the cathode was measured using pressure transducers (Variohm, UK). The fuel cell temperature was controlled at $40^{\circ} \mathrm{C}$ for each test.

\subsection{Neutron imaging}

The experiments were performed at the CONRAD beamline facility at the Helmholtz-Zentrum Berlin (HZB). The setup for neutron imaging is outlined in [42], [47]. All of the tests were conducted in the through-plane orientation, where the MEA is perpendicular to the beam, allowing visualization of liquid water across the entire active area of the fuel cell. An imaging field-of-view of $56 \times 67 \mathrm{~mm}^{2}$ with $26 \mu \mathrm{m}$ pixel $^{-1}$ resolution was acquired [51]. Each image was taken with an exposure time of $5 \mathrm{~s}$. A detailed calculation procedure of the local water thickness is outlined in [47].

The pixel size $(26 \mu \mathrm{m})$ of neutron radiographs is not sufficient to identify the microstructure of the metal foam (pore sizes range from 50-300 $\mu \mathrm{m}$ ). However, the vertical single-channel serpentine geometry of the anode flow-field (Fig. 1 (b)) allows differentiating the electrode at which the liquid water resides. 
(a)

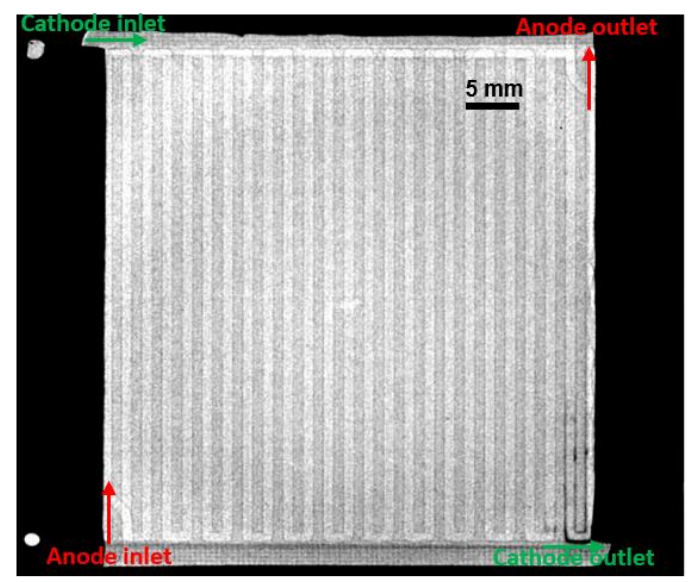

(b)

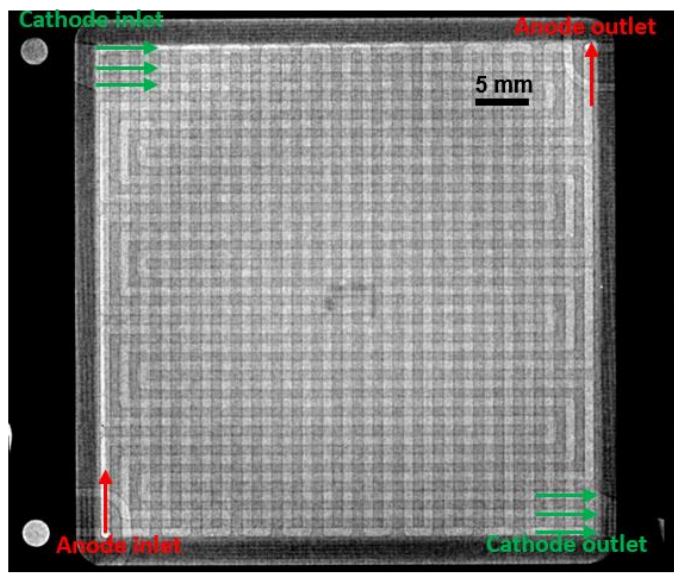

Fig. 3. Radiographs of dry cells with (a) metal foam flow-field and (b) three-channel serpentine flow-field. A vertical single-channel serpentine flow-field was used in both cases.

\section{Results and discussion}

Fig. 4 (a) compares the performance of the metal foam and conventional serpentine flow-field designs without external humidification. All of the experiments were started at open circuit potential and the current density was incrementally changed every $1200 \mathrm{~s}$ at $200 \mathrm{~mA} \mathrm{~cm}{ }^{-2}$ intervals. Each polarization was repeated twice and averaged. At low current density region $\left(\leq 200 \mathrm{~mA} \mathrm{~cm}{ }^{-2}\right)$, the PEFC with metal foam flow-field exhibits a slight increase in performance over the serpentine design. The performance difference becomes significant at high current densities, where the voltage of the metal foam design is approximately $50 \%$ higher than that of the serpentine design at $1000 \mathrm{~mA} \mathrm{~cm}$. Moreover, the metal foam design exhibits a peak power density of $853 \mathrm{~mW} \mathrm{~cm}{ }^{-2}$ at $1600 \mathrm{~mA} \mathrm{~cm} \mathrm{~cm}^{-2}$, which is approximately twice that of the peak power density of the serpentine design. This agrees with previous studies where metal foam flow-fields outperformed conventional serpentine flow-fields [17], [22], [24]-[26]. One possible explanation for the enhanced performance is the ability of the metal foam to deliver more uniform distribution of reactant gases and generated water across the active area due to the homogeneous porous structure [26], [29], [30]. The presence of gas channel and land in the serpentine flow-field designs render reactant gas and water distribution highly non-uniform [13], [15], [18], [52]-[54]. 
The Ohmic resistance of a PEFC can be measured with HFR, and the change in HFR with respect to the change in operating condition can be used as a proxy for the level of membrane hydration [55], [56]. The change in HFR with respect to current density of the metal foam and serpentine based PEFCs is presented in Fig. 4(b). The metal foam design exhibits $\sim 38 \%$ lower HFR than the serpentine design at $1000 \mathrm{~mA} \mathrm{~cm}{ }^{-2}$. The metal flow-field has a lower intrinsic Ohmic resistance due to its high electrical conductivity [57][54]. The HFR initially decreases with current density as the membrane gets more hydrated due to generation of water. The HFR starts to increase for the serpentine design above $800 \mathrm{~mA} \mathrm{~cm}^{-2}$. This is attributed to the onset of membrane dehydration at high temperature [58]. Membrane dehydration is also observed for the metal foam design but at a higher current density of $1400 \mathrm{~mA} \mathrm{~cm}^{-2}$, indicating that the latter design is more tolerant to dehydration at high current density.

In terms of the cathode pressure drop (Fig. 4 (b)), fixed stoichiometry results in an increase in pressure drop with current density. The metal foam flow-field displays half of the pressure drop compared to the conventional serpentine design (at $1000 \mathrm{~mA} \mathrm{~cm}{ }^{-2}$ ), reducing the parasitic power for pumping. The ability of the metal foam flow-field to deliver a low-pressure drop has therefore great potential from a technical point of view. On the other hand, the much lower pressure drop renders metal foam designs more susceptible to flooding.

(a)

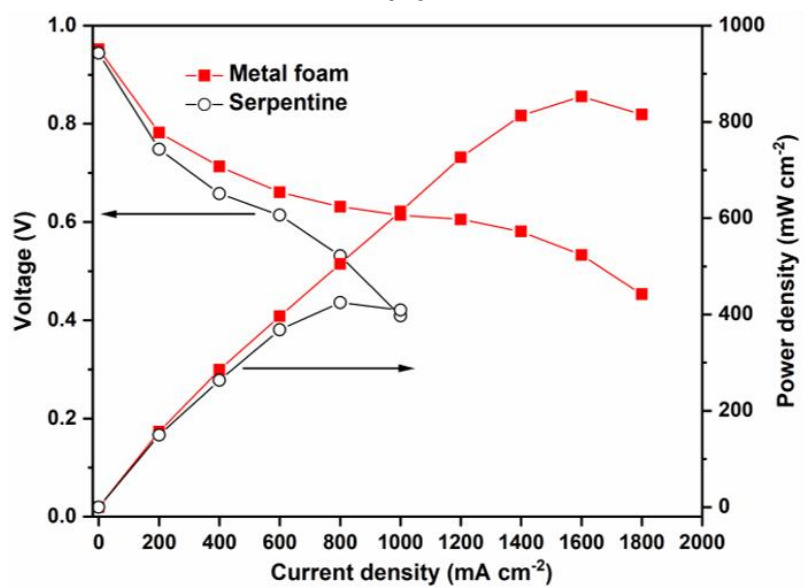

(b)

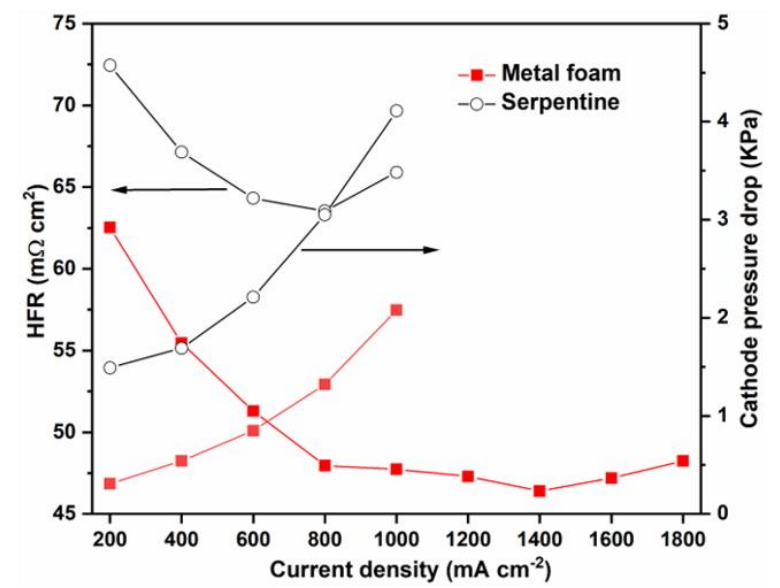

Fig. 4 (a) Polarization curves, (b) high-frequency resistance (HFR) and cathode pressure drop obtained for metal foam flow-field and conventional serpentine flow-field. 
The water pattern evolution within the metal foam flow-field based PEFC is presented in time resolved neutron images (Fig. 5 (a-d)). The cell was operated galvanostatically at $100 \mathrm{~mA} \mathrm{~cm}$ over $^{-2}$ 1200 seconds. Water continues to build up in the pores of the metal foam flow-field as shown in Fig. 5 (e). A gradient in water distribution is established after $\sim 150 \mathrm{~s}$ with greater water content (30-185 $\mu \mathrm{m})$ towards the bottom right of the active area. This is ascribed to a combined effect of gravity and convective force of the cathode gas flowing from top left to bottom right of the electrode. Water accumulation at low current density $\left.(100 \mathrm{~mA} \mathrm{~cm})^{-2}\right)$ is associated with insufficient gas flow for convective water removal across the channel and electrode. The amount of liquid water in the anode is minimal at $150 \mathrm{~s}$ and, hence, it can be assumed that most of the water is present in the cathode as a consequence of electrochemical reaction and electroosmotic drag. Water droplets appear on the channel walls of the anode flow-field as time passes (red arrows in Fig. 5 (b)). This agrees with neutron imaging studies on conventional cathode flow-fields [15], [43], [59]-[62] and is associated with the back-diffusion of generated water into the anode [55]. The emerged droplets in the anode channels grow and spread across the width of the gas channel (red arrows in Fig. 5 (d)). Water in the cathode progressively covers almost the entire cell active area (Fig. 5 (d)), exhibiting macroscopic uniformity in water distribution. 
(a)

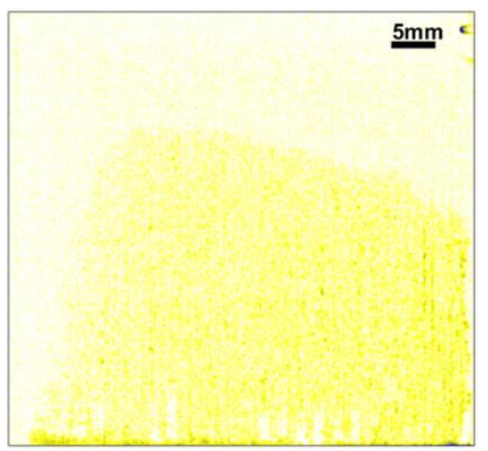

(c) (b)

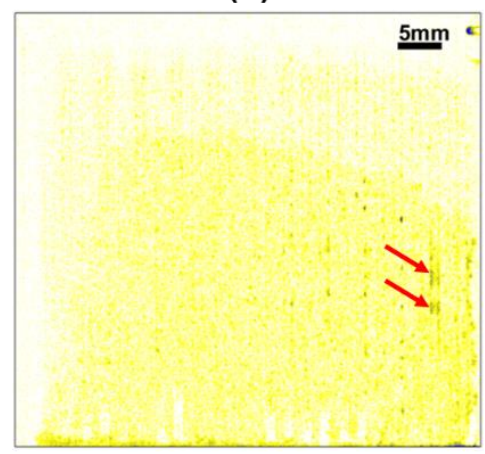

(d) (e)

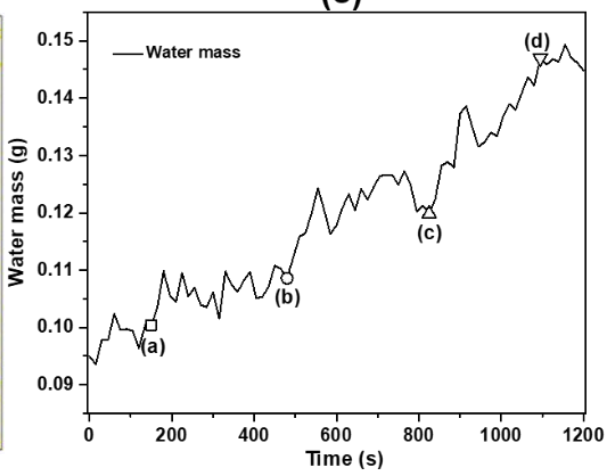

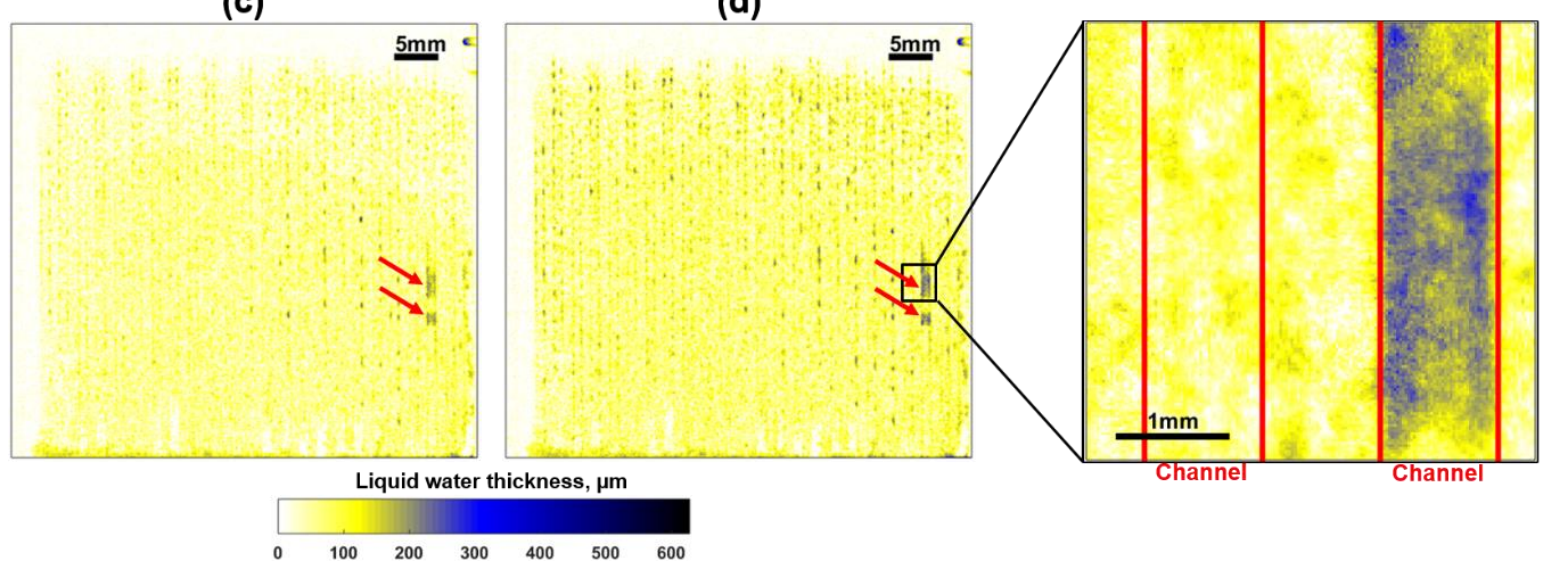

Fig. 5 (a-d) Time resolved neutron images of the metal foam flow-field based PEFC and (e) the evolution of the water mass. The cell was operated under galvanostatic mode at $100 \mathrm{~mA} \mathrm{~cm}{ }^{-2}$. The anode channel position in the magnified view of Fig. 4 (d) are masked in red.

Fig. 6 (a) and (b) compare the averaged liquid water (thickness) distribution for different flow-field designs operated galvanostatically at $500 \mathrm{~mA} \mathrm{~cm}^{-2}$ (average current density) over 1200 seconds. One feature shared amongst the two flow-fields is that liquid slugs appear in the vertical anode channels. The effect of gravity on the water accumulation can be seen in Fig. 6 (a) and (b); more liquid water tends to accumulate in vertical anode channels where hydrogen flows upwards (red arrows in Fig. 6), compared to those channels where hydrogen flows downwards (green arrows in Fig. 6). This phenomenon has been reported in [63]. Additionally, liquid water is observed around the bottom of the anode channel bends (dashed black boxes in Fig. 6 (a) and (b)) in both designs, which is typically observed in serpentine configuration [15], [40], [42]. This is caused by gas flow recirculation, stagnation and little pressure drop in these regions. However, the cathode water distribution between the two flow-field designs is different. Liquid water was mainly found in some of the horizontal channels (purple boxes in Fig. 6 (b)) for the serpentine case. A more uniform water distribution was 
achieved with the metal foam design (zone outlined in purple in Fig. 6 (a)), where water content appears across a much wider region of the active area.

As seen in Fig. 6 (c), the metal foam design exhibits a $\sim 102 \%$ increase in the averaged mass of accumulated liquid water, compared to the serpentine design. The dynamics of water accumulation in the serpentine flow-field occur in two different stages; the first stage where water rapidly accumulates $(t \leq 500 \mathrm{~s})$ followed by, the second stage where a plateau in total water mass is reached $(t>500 \mathrm{~s})$. In contrast, the water build-up in the metal foam flow-field continues to grow for the duration of the current hold, indicating that the use of such a design may lead to the elevated susceptibility to flooding under low current density due to depreciated water removal ability. It is anticipated that such issue will exacerbate at high relative humidity.

In terms of voltage evolution over the same period (Fig. 6 (d)), the cell with metal foam flow-field exhibits higher performance than the serpentine design. As the serpentine design has limited paths for both gas transport and water removal, it is anticipated that any water-blocked channel in such a design is more susceptible to flooding. Although water accumulation is observed in the metal foam design, its porous structure with favourable gas channel connectivity provide numerous alternative gas transport pathways, thereby enhancing gas diffusion towards the catalyst layer and delivering better performance. 
(a)

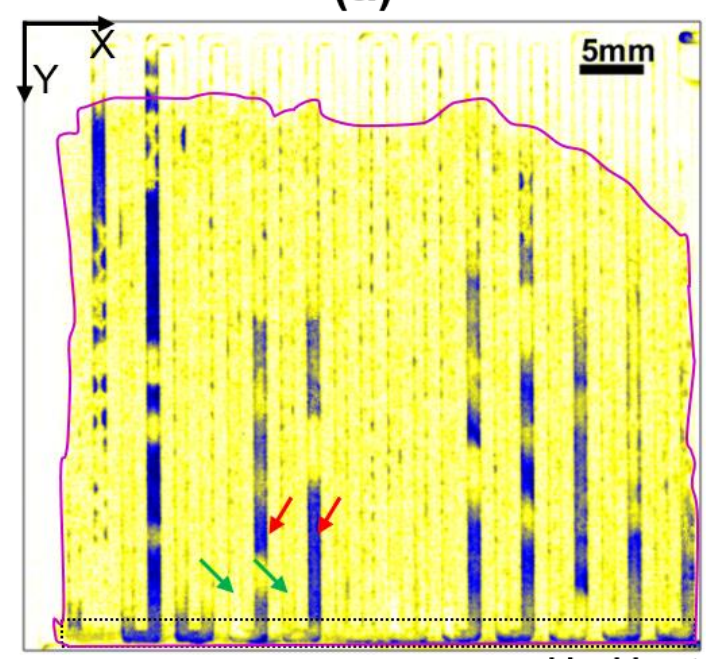

(b)

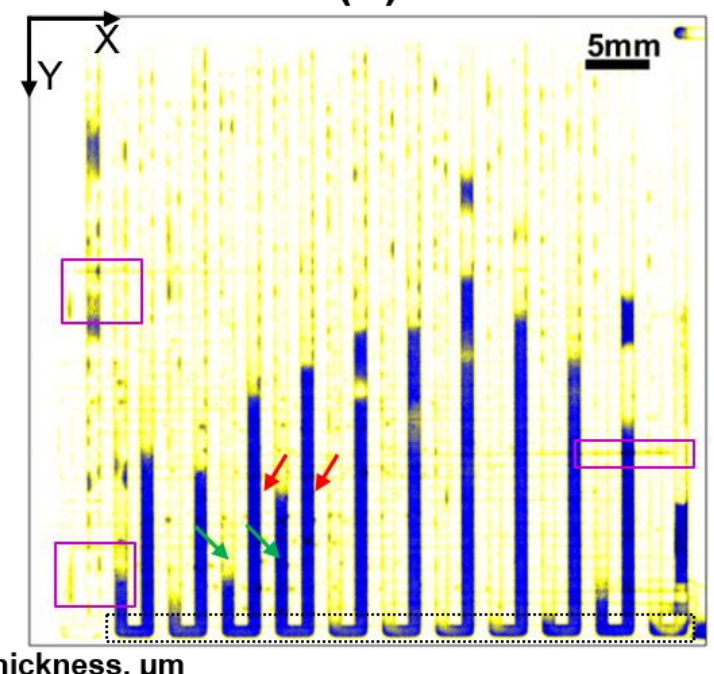

(d)
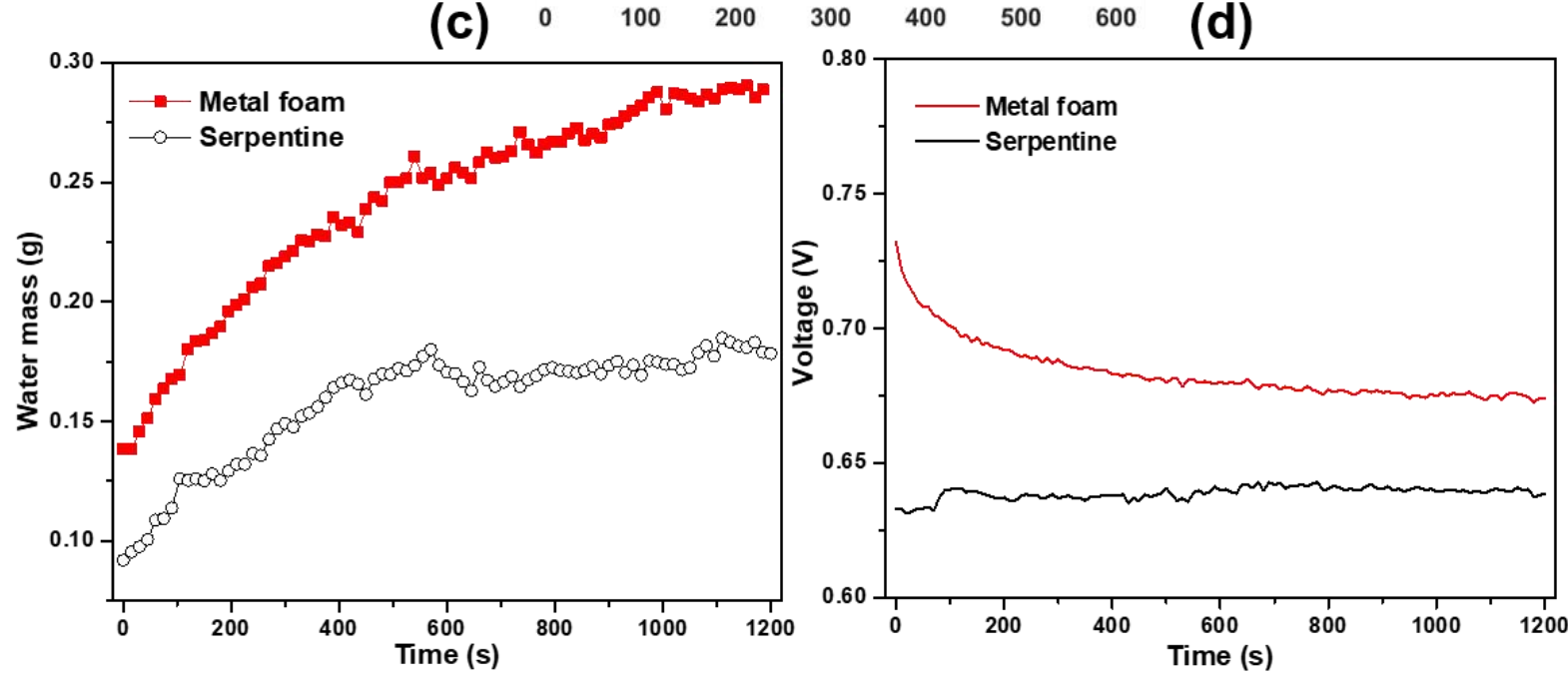

Fig. 6. (a) Time-averaged neutron images showing water thickness distribution in metal foam flow-field and (b) conventional serpentine flow-field (b). The cell was operated under galvanostatic mode at $500 \mathrm{~mA} \mathrm{~cm}$-2 over 1200 seconds. The variation in (c) accumulated water mass and (d) voltage over this period.

Severe dehydration is observed for the serpentine flow-field design at $1000 \mathrm{~mA} \mathrm{~cm}{ }^{-2}$ (Fig. 7 (b)), where a significant portion of water in the cathode has been removed. Additionally, water in the anode channels significantly decreases. An overall decrease of $53 \%$ (against the case for $500 \mathrm{~mA} \mathrm{~cm}{ }^{-2}$ ) in the amount of accumulated water was shown in the serpentine design (Fig. 7 (d)), althrough twice as much water is generated at $1000 \mathrm{~mA} \mathrm{~cm}^{-2}$ against $500 \mathrm{~mA} \mathrm{~cm}-2$ (within the same period). This can be ascribed to the higher local MEA temperature and gas velocity which enhances convective liquid 
water removal when transitioning to a higher current density [15], [43]. Consequently, the voltage continues to decline with time (Fig. 7 (d)), indicating an onset of membrane dehydration.

The metal foam design exhibits an overall decrease of $31 \%$ (against the case for $500 \mathrm{~mA} \mathrm{~cm}^{-2}$ ) in the amount of accumulated water. On the other hand, the total mass of water in the metal foam design (Fig. 7 (c)) still exhibits a $\sim 127 \%$ increase, compared to the serpentine design at $1000 \mathrm{~mA} \mathrm{~cm}{ }^{-2}$, indicating that the metal foam design is more tolerant to dehydration at higher current density. The results imply that the generated water is 'stored' in the pores of the metal foam and is not ejected from the cell by the same extent as in the conventional flow-fields, thereby providing additional humidification to the system [19]. This is also reflected in the slower decline in potential in the metal foam based PEFC, as shown in Fig. 7 (d). 
(a)

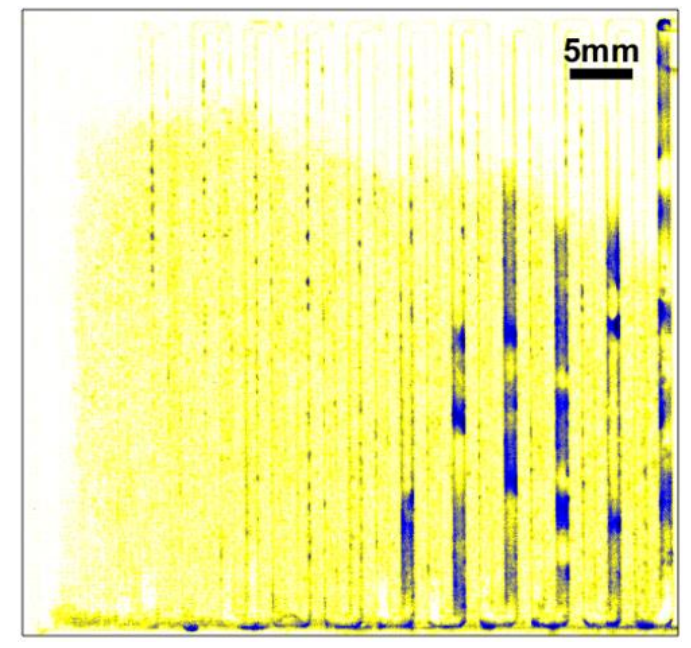

(b)

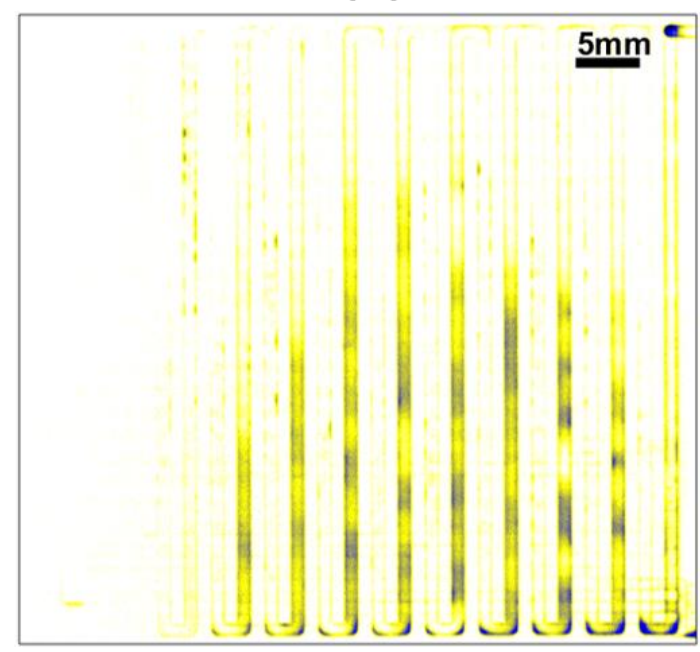

(d)
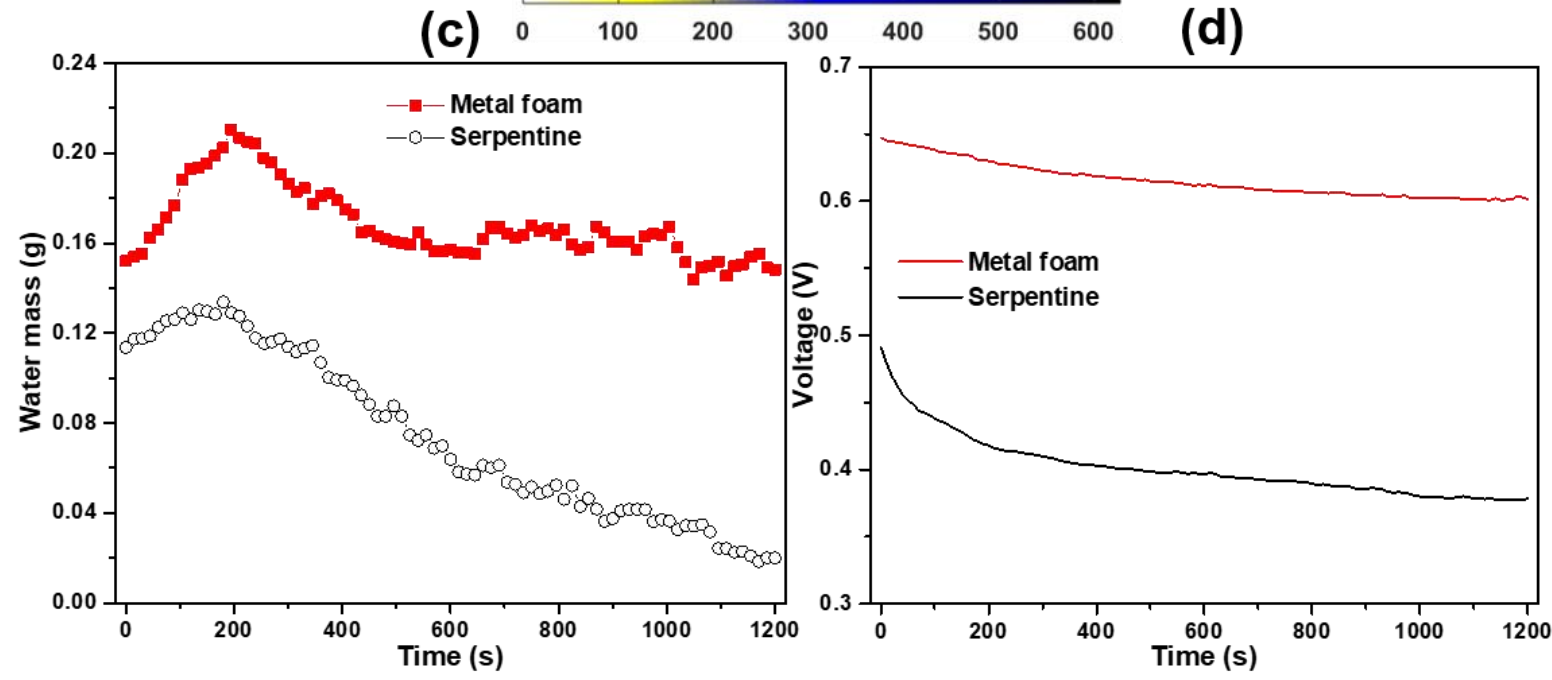

Fig. 7. Time-averaged neutron images showing water thickness distribution in metal foam flow-field (a) and conventional serpentine flow-field (b). The cell was operated under galvanostatic mode at $1000 \mathrm{~mA} \mathrm{~cm}{ }^{-2}$ over 1200 seconds. The variation in (c) accumulated water mass and (d) voltage over this period.

It has been reported that the non-uniform distribution of generated water can exacerbate degradation of MEAs by mechanical stresses. Such issues can induce the fuel cell performance loss and longevity decay [13], [15]. Therefore, it is imperative to study the homogenity of the water distribution across the entire cell active area [64]. Here, the time-averaged neutron images in Fig. 6 (a) and (b) are employed. 
The averaged water thickness over the x-axis (see the coordinate system in Fig. 6 (a) and (b)) at each y position, $\delta_{\mathrm{H}_{2} \mathrm{O}\left(y_{\text {ave }}\right)}$, is given by:

$$
\delta_{H_{2} O\left(y_{\text {ave }}\right)}=\frac{\int_{x=0}^{x_{\max }} \delta_{H_{2} \mathrm{O}(x, y)} \cdot d x}{x_{\max }}
$$

While the averaged water thickness over the y-axis (see the coordinate system in Fig. 6 (a) and (b)) at each x position, $\delta_{\mathrm{H}_{2} \mathrm{O}(x)}$, is given by:

$$
\delta_{H_{2} O\left(x_{\text {ave }}\right)}=\frac{\int_{y=0}^{y_{\max }} \delta_{H_{2} \mathrm{O}(x, y) \cdot d y}}{y_{\max }}
$$

where $\delta_{H_{2} 0(x, y)}$ is the local water thickness. The uniformity of water thickness distribution in both axises is subsequently plotted in Fig. 8 (a) and (b).

According to Fig. 8 (a), one feature that is shared between the two designs is that liquid water tends to condense in the lower-half of the active area (larger y-position value) due to gravity. A more uniform water distribution along the $y$-axis is indentified in the metal foam flow-field, with a standard deviation of $\sim 13 \mu \mathrm{m}$ (Fig. 8 (c)), compared to $\sim 49 \mu \mathrm{m}$ for the serpentine design.

In terms of water distribution along the x-axis (Fig. 8 (b)), the periodic 'peaks' and 'valleys' are observed in the local $\delta_{\mathrm{H}_{2} \mathrm{O}(x)}$ for both designs. This feature is due to the land/channel structure in their shared anode serpentine flow-field, rendering the increasing water distribution gradient [15], indicating the drawback of this design. A smaller standard deviation $(\sim 49 \mu \mathrm{m}$, Fig. 8 (c) $)$ of the water thickness along the $\mathrm{x}$-axis is found in the metal foam flow-field compared to the serpentine design $(\sim 75 \mu \mathrm{m}$. In terms of the standard deviation of the liquid water thickness distribution across the entire cell active area (Fig. 8 (c)), the metal foam flow-field exhibits a $~ 99 \%$ decrease in variation compared to the serpentine design. The results indicate that more uniform water distribution is achieved by the metal foam flow-field. This can be ascribed to the absence of the land/channel configuration as this design improves the uniformity in reactant distribution across the electrode. 
(a)

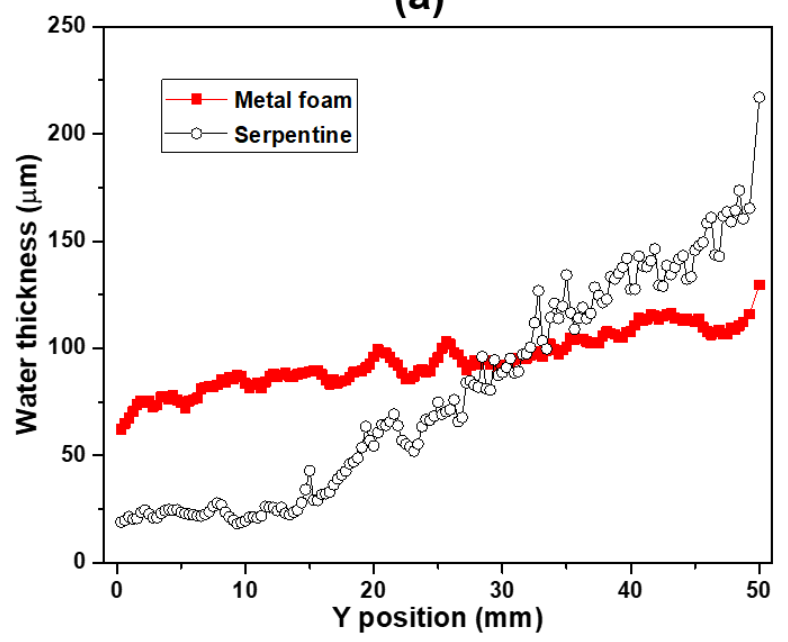

(c)

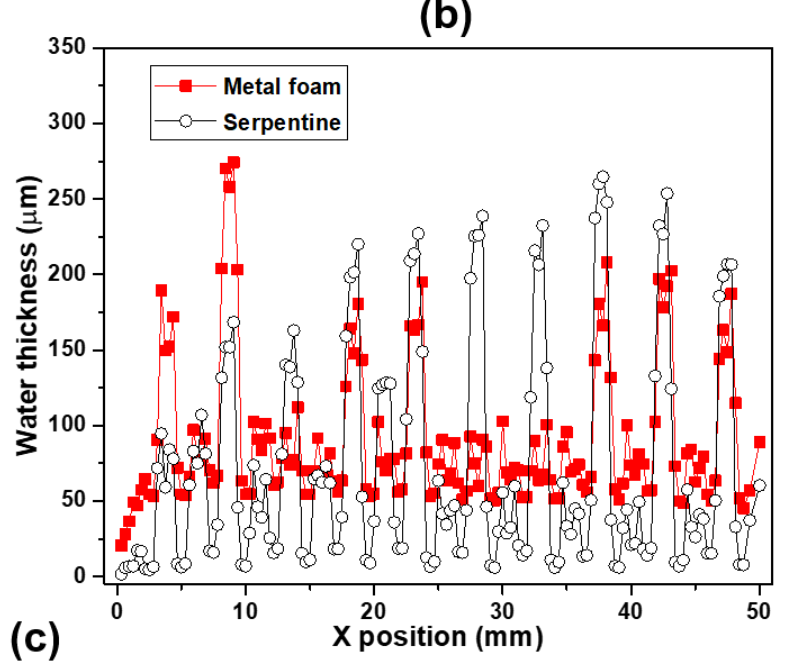

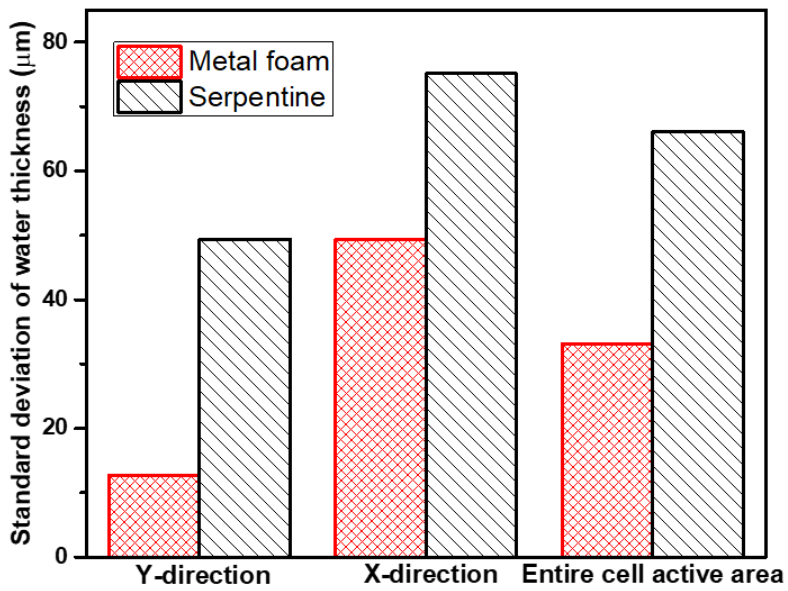

Fig. 8. Uniformity (a, b) and standard deviation (c) of water distribution along the y-axis (a) and $\mathrm{x}$-axis (b) (see the coordinate system in Fig. $6(a, b))$ of different flow-field designs operating at $500 \mathrm{~mA} \mathrm{~cm}^{-2}$.

\section{Conclusion}

The water formation, accumulation and removal within the metal foam and serpentine flow-field based PEFCs have been investigated using in-operando neutron radiography. In particular, this study allows comparing the uniformity of water thickness distribution in both flow-field designs. Additionally, the corresponding cell performance of two designs are recorded along with neutron images.

The results reveal severe dehydration for the serpentine design when the cell was operated at 1000 $\mathrm{mA} \mathrm{cm}^{-2}$, On the contrary, the metal foam flow-field based PEFC shows greater tolerance to 
dehydration at the same current density, exhibiting a $\sim 50 \%$ increase in voltage, $\sim 127 \%$ increase in total water mass and $\sim 38 \%$ decrease in HFR, compared to the serpentine flow-field design. This is ascribed to the effective 'storage' of water (generated by the electrochemical reaction) in the pores of the metal foam. In terms of the uniformity of water distribution in both designs, the metal foam flowfield exhibits a $~ 99 \%$ decrease in the standard deviation of the water thickness distribution across the entire cell active area against the serpentine design. The absence of a land/channel configuration in the metal foam flow-field designs improves the uniformity in reactant distribution across the electrode, contributing to a $\sim 101 \%$ increase in maximum power density than the serpentine design. However, the metal foam flow-field design exhibits much higher water accumulation in the low current density region caused by the weaker water removal capability. Optimizing fuel cell operating condition and foam microstructure would partly mitigate flooding in the metal foam flow-field based PEFC, which will form the basis of future work.

\section{Acknowledgements}

The authors gratefully acknowledge the funding from the EPSRC ((EP/M014371/1 and EP/M009394/1) for supporting Electrochemical Innovation Lab and to the China Scholarship Council, UCL Faculty of Engineering Sciences Dean's Scholarship, STFC Futures Early Career Award (ST/R006873/1) and Sichuan Province Science and Technology Fund (2019YJ0236) for supporting $\mathrm{Wu}$ Yunsong.

\section{References}

[1] V. Mehta, J.S. Cooper, Review and analysis of PEM fuel cell design and manufacturing, J. Power Sources 2003;114(1):32-53.

[2] I. Tolj, D. Bezmalinovic, F. Barbir, Maintaining desired level of relative humidity throughout a fuel cell with spatially variable heat removal rates, Int. J. Hydrogen Energy 2011; 36(20):13105-13.

[3] C. Lebreton, M. Benne, C. Damour, N. Yousfi-Steiner, B. Grondin-Perez, D. Hissel, J.P. Chabriat, Fault Tolerant Control Strategy applied to PEMFC water management, Int. J. Hydrogen Energy 2015; 40(33):10636-46.

[4] N. Bunmark, S. Limtrakul, M.W. Fowler, T. Vatanatham, J. Gostick, Assisted water management in a PEMFC with a modified flow field and its effect on performance, Int. J. Hydrogen Energy 2010; 35(13):6887-96.

[5] N.J. Cooper, T. Smith, A.D. Santamaria, J.W. Park, Experimental optimization of parallel and interdigitated PEMFC flow-field channel geometry, Int. J. Hydrogen Energy 2016; 41(2):1213-23. 
[6] A.P. Manso, F.F. Marzo, J. Barranco, X. Garikano, M.G. Mujika, Influence of geometric parameters of the flow fields on the performance of a PEM fuel cell. A review, Int. J. Hydrogen Energy 2012; 37(20)15256-87.

[7] D.J.L. Brett, N.P. Brandon, Review of Materials and Characterization Methods for Polymer Electrolyte Fuel Cell Flow-Field Plates, Journal of fuel cell science and technology 2007; 4(1), 29-44.

[8] X. Li, I. Sabir, Review of bipolar plates in PEM fuel cells: Flow-field designs, Int. J. Hydrogen Energy 2005; 30(4):359-71.

[9] J. Wang, Theory and practice of flow field designs for fuel cell scaling-up: A critical review, Appl Energy 2015; 157: 640-63.

[10] A. Ghanbarian, M.J. Kermani, J. Scholta, M. Abdollahzadeh, Polymer electrolyte membrane fuel cell flow field design criteria - Application to parallel serpentine flow patterns, Energy Convers. Manag 2018; 166: 281-96.

[11] A.P. Sasmito, J.C. Kurnia, A.S. Mujumdar, Numerical evaluation of various gas and coolant channel designs for high performance liquid-cooled proton exchange membrane fuel cell stacks, Energy 2012; 44(1):278-91.

[12] X. Wang, W. Yan, Y. Duan, F. Weng, G. Jung, C. Lee, Numerical study on channel size effect for proton exchange membrane fuel cell with serpentine flow field, Energy Convers. Manag 2010; 51(5):959-68.

[13] P. Trogadas, J.I.S. Cho, T.P. Neville, J. Marquis, B. Wu, D.J.L. Brett, M.O. Coppens, A lung-inspired approach to scalable and robust fuel cell design, Energy Environ. Sci 2018; 11(1):136-43.

[14] J.I.S. Cho, T.P. Neville, P. Trogadas, J. Bailey, P. Shearing, D.J.L. Brett, M. Coppens, Capillaries for water management in polymer electrolyte membrane fuel cells, Int. J. Hydrogen Energy 2018; 43(48):21949-58.

[15] Y. Wu, J.I.S. Cho, T.P. Neville, Q. Meyer, R. Zeische, P. Boillat, M. Cochet, P.R. Shearing, D.J.L. Brett, Effect of serpentine flow-field design on the water management of polymer electrolyte fuel cells: An in-operando neutron radiography study, J. Power Sources. 2018; 399:254-63.

[16] O.J. Murphy, A. Cisar, E. Clarke, Low-cost light weight high power density PEM fuel cell stack, Electrochim. Acta 1998; 43(24):3829-40.

[17] B.T. Tsai, C.J. Tseng, Z.S. Liu, C.H. Wang, C.I. Lee, C.C. Yang, S.K. Lo, Effects of flow field design on the performance of a PEM fuel cell with metal foam as the flow distributor, Int. J. Hydrogen Energy 2012; 37(17):13060-6.

[18] C.J. Tseng, B.T. Tsai, Z.S. Liu, T.C. Cheng, W.C. Chang, S.K. Lo, A PEM fuel cell with metal foam as flow distributor, Energy Convers. Manag 2012; 62:14-21.

[19] C.-Y. Ahn, M.S. Lim, W. Hwang, S. Kim, J.E. Park, J. Lim, I. Choi, Y.-H. Cho, Y.-E. Sung, Effect of Porous Metal Flow Field in Polymer Electrolyte Membrane Fuel Cell under Pressurized Condition, Fuel Cells 2017; 17(5):652-61.

[20] A. Kumar, R.G. Reddy, Modeling of polymer electrolyte membrane fuel cell with metal foam in the flow-field of the bipolar/end plates, J. Power Sources 2003; 114(1):54-62.

[21] T. Kariya, T. Hirono, H. Funakubo, T. Shudo, Effects of the porous structures in the porous flow field type separators on fuel cell performances, Int. J. Hydrogen Energy 2014; 39(27) :15072-80.

[22] W. Yuan, Y. Tang, X. Yang, Z. Wan, Porous metal materials for polymer electrolyte membrane fuel cells-A review, Appl. Energy 2012; 94:309-29.

[23] D.K. Shin, J.H. Yoo, D.G. Kang, M.S. Kim, Effect of cell size in metal foam inserted to the air channel of polymer electrolyte membrane fuel cell for high performance, Renew. Energy 2018; 115:663-75.

[24] M. Kozakai, K. Date, Y. Tabe, T. Chikahisa, Improving gas diffusivity with bi-porous flow-field in polymer electrolyte membrane fuel cells, Int. J. Hydrogen Energy 2016; 41(30) 13180-9.

[25] S. Huo, N. James, T. Lee, J. Wan, K. Jiao, Experimental investigation on PEM fuel cell cold start behavior containing porous metal foam as cathode flow distributor, Appl. Energy 2017; 203:101-14. 
[26] J.E. Park, J. Lim, S. Kim, I. Choi, C.Y. Ahn, W. Hwang, M.S. Lim, Y.H. Cho, Y.E. Sung, Enhancement of mass transport in fuel cells using three-dimensional graphene foam as flow field, Electrochim. Acta 2018; 265:488-96.

[27] J.E. Park, W. Hwang, M.S. Lim, S. Kim, C.Y. Ahn, O.H. Kim, J.G. Shim, D.W. Lee, J.H. Lee, Y.H. Cho, Y.E. Sung, Achieving breakthrough performance caused by optimized metal foam flow field in fuel cells, Int. J. Hydrogen Energy 2019; 44(39):22074-84.

[28] Y. Awin, N. Dukhan, Experimental performance assessment of metal-foam flow fields for proton exchange membrane fuel cells, Appl. Energy 2019; 252:113458-65.

[29] A. Jo, H. Ju, Numerical study on applicability of metal foam as flow distributor in polymer electrolyte fuel cells (PEFCs), Int. J. Hydrogen Energy 2018; 43(30):14012-26.

[30] Z. Bao, Z. Niu, K. Jiao, Numerical simulation for metal foam two-phase flow field of proton exchange membrane fuel cell, Int. J. Hydrogen Energy 2019; 44(12):6229-44.

[31] A. Jo, S. Ahn, K. Oh, W. Kim, H. Ju, Effects of metal foam properties on flow and water distribution in polymer electrolyte fuel cells (PEFCs), Int. J. Hydrogen Energy 2018; 43(30):14034-46.

[32] Y. Tabe, T. Nasu, S. Morioka, T. Chikahisa, Performance characteristics and internal phenomena of polymer electrolyte membrane fuel cell with porous flow field, J. Power Sources 2013; 238:21-8.

[33] A. Fly, D. Butcher, Q. Meyer, M. Whiteley, A. Spencer, C. Kim, P.R. Shearing, D.J.L. Brett, R. Chen, Characterisation of the diffusion properties of metal foam hybrid flow-fields for fuel cells using optical flow visualisation and X-ray computed tomography, J. Power Sources 2018; 395:171-8.

[34] A. Fly, Q. Meyer, M. Whiteley, F. Iacoviello, T. Neville, P.R. Shearing, D.J.L. Brett, C. Kim, R. Chen, X-ray tomography and modelling study on the mechanical behaviour and performance of metal foam flow-fields for polymer electrolyte fuel cells, Int. J. Hydrogen Energy 2019; 44(14): 7583-95.

[35] A. Bazylak, Liquid water visualization in PEM fuel cells: A review, Int. J. Hydrogen Energy 2009; 34(9):3845-57.

[36] P. Boillat, E.H. Lehmann, P. Trtik, M. Cochet, Neutron imaging of fuel cells - Recent trends and future prospects, Curr. Opin. Electrochem 2017; 5:3-10.

[37] R. Satija, D.L. Jacobson, M. Arif, S.A. Werner, In situ neutron imaging technique for evaluation of water management systems in operating PEM fuel cells, J. Power Sources. $2004 ; 129(2): 238-45$.

[38] J.P. Owejan, T.A. Trabold, D.L. Jacobson, M. Arif, S.G. Kandlikar, Effects of flow field and diffusion layer properties on water accumulation in a PEM fuel cell, Int. J. Hydrogen Energy 2007; 32(17):4489-502.

[39] Q. Meyer, S. Ashton, R. Jervis, D.P. Finegan, P. Boillat, M. Cochet, O. Curnick, T. Reisch, P. Adcock, P.R. Shearing, D.J.L. Brett, The Hydro-electro-thermal Performance of Air-cooled, Open-cathode Polymer Electrolyte Fuel Cells: Combined Localised Current Density, Temperature and Water Mapping, Electrochim. Acta 2015; 180:307-15.

[40] H. Murakawa, K. Sugimoto, N. Kitamura, M. Sawada, H. Asano, N. Takenaka, Y. Saito, Visualization of Water Accumulation Process in Polymer Electrolyte Fuel Cell Using Neutron Radiography, in: Phys. Procedia 2015; 69:607-11.

[41] A. Iranzo, P. Boillat, J. Biesdorf, A. Salva, Investigation of the liquid water distributions in a $50 \mathrm{~cm}^{2}$ PEM fuel cell: Effects of reactants relative humidity, current density, and cathode stoichiometry, Energy 2015; 82:914-21.

[42] Y. Wu, J.I.S. Cho, X. Lu, L. Rasha, T.P. Neville, J. Millichamp, R. Ziesche, N. Kardjilov, H. Markötter, P. Shearing, D.J.L. Brett, Effect of compression on the water management of polymer electrolyte fuel cells : An in-operando neutron radiography study 2019; 412:597-605.

[43] J.I.S. Cho, T.P. Neville, P. Trogadas, Q. Meyer, Y. Wu, R. Ziesche, P. Boillat, M. Cochet, V. Manzi-orezzoli, P. Shearing, D.J.L. Brett, Visualization of liquid water in a lung-inspired flowfield based polymer electrolyte membrane fuel cell via neutron radiography, Energy 2019; 170: 14-21. 
[44] E. Coz, J. Théry, P. Boillat, V. Faucheux, D. Alincant, P. Capron, G. Gébel, Water management in a planar air-breathing fuel cell array using operando neutron imaging, J. Power Sources 2016; 331:535-43.

[45] A. Iranzo, A. Salva, P. Boillat, J. Biesdorf, E. Tapia, F. Rosa, Water build-up and evolution during the start-up of a PEMFC: Visualization by means of Neutron Imaging, Int. J. Hydrogen Energy 2017; 42(19):13839-49.

[46] P.A. García-Salaberri, D.G. Sánchez, P. Boillat, M. Vera, K.A. Friedrich, Hydration and dehydration cycles in polymer electrolyte fuel cells operated with wet anode and dry cathode feed: A neutron imaging and modeling study, J. Power Sources 2017; 359:634-55.

[47] Y. Wu, Q. Meyer, F. Liu, L. Rasha, J.I.S. Cho, T.P. Neville, J. Millichamp, R. Ziesche, N. Kardjilov, P. Boillat, H. Markötter, I. Manke, M. Cochet, P. Shearing, D.J.L. Brett, Investigation of water generation and accumulation in polymer electrolyte fuel cells using hydroelectrochemical impedance imaging, J. Power Sources 2019; 414:272-7.

[48] K. Yoshizawa, K. Ikezoe, Y. Thsaki, D. Kramer, E.H. Lehmann, G.G. Scherer, Analysis of gas diffusion layer and flow-field design in a PEMFC using neutron radiography, $J$. Electrochem. Soc 2008; 155(3):B223-7.

[49] Y. Sim, J. Kwak, S.Y. Kim, Y. Jo, S. Kim, S.Y. Kim, J.H. Kim, C.S. Lee, J.H. Jo, S.Y. Kwon, Formation of 3D graphene-Ni foam heterostructures with enhanced performance and durability for bipolar plates in a polymer electrolyte membrane fuel cell, J. Mater. Chem. A 2018; 6:1504-12.

[50] Y.H. Lee, S.M. Li, C.J. Tseng, C.Y. Su, S.C. Lin, J.W. Jhuang, Graphene as corrosion protection for metal foam flow distributor in proton exchange membrane fuel cells, Int. J. Hydrogen Energy 2017; 42(34):22201-7.

[51] Kardjilov, N., Hilger, A. and Manke, I. "Conrad-2: cold neutron tomography and radiography at ber ii (v7)." Journal of large-scale research facilities JLSRF 2016; 2: 98.

[52] D.H. Jeon, S. Greenway, S.Ã. Shimpalee, J.W. Van Zee, The effect of serpentine flow-field designs on PEM fuel cell performance, Int. J. Hydrogen Energy 2008; 33(3):1052-66.

[53] N. Limjeerajarus, P. Charoen-Amornkitt, Effect of different flow field designs and number of channels on performance of a small PEFC, Int. J. Hydrogen Energy 2015; 40(22):7144-58.

[54] X. Wang, Y. Duan, W. Yan, X. Peng, Local transport phenomena and cell performance of PEM fuel cells with various serpentine flow field designs, J. Power Sources 2008(1); 175:397-407.

[55] D.J.L. Brett, S. Atkins, N.P. Brandon, N. Vasileiadis, V. Vesovic, A.R. Kucernak, Membrane resistance and current distribution measurements under various operating conditions in a polymer electrolyte fuel cell, J. Power Sources 2007; 172(1):2-13.

[56] O.A. Obeisun, Q. Meyer, E. Engebretsen, D.P. Finegan, J.B. Robinson, G. Hinds, P.R. Shearing, D.J.L. Brett, Study of water accumulation dynamics in the channels of an opencathode fuel cell through electro-thermal characterisation and droplet visualisation, Int. J. Hydrogen Energy 2015; 40(46):16786-96.

[57] J.G. Carton, A.G. Olabi, Three-dimensional proton exchange membrane fuel cell model : Comparison of double channel and open pore cellular foam flow plates, Energy 2017; 136:185-95.

[58] V.A.R. Ilie, S. Martemianov, A. Thomas, Investigation of the local temperature and overheat inside the membrane electrode assembly of PEM fuel cell, Int. J. Hydrogen Energy 2016; 41(34): 15528-37.

[59] P. Oberholzer, P. Boillat, R. Siegrist, R. Perego, A. Kästner, E. Lehmann, GG. Scherer, A. Wokaun, Cold-start of a PEFC visualized with high resolution dynamic in-plane neutron imaging. Journal of The Electrochemical Society 2011; 159(2):B235-45.

[60] A. Iranzo, P. Boillat, Liquid water distribution patterns featuring back-diffusion transport in a PEM fuel cell with neutron imaging, Int. J. Hydrogen Energy 2014; 39(30):17240-5.

[61] Q. Meyer, S. Ashton, P. Boillat, M. Cochet, E. Engebretsen, D.P. Finegan, X. Lu, J.J. Bailey, N. Mansor, R. Abdulaziz, O.O. Taiwo, R. Jervis, S. Torija, P. Benson, S. Foster, P. Adcock, P.R. Shearing, D.J.L. Brett, Effect of gas diffusion layer properties on water distribution across aircooled, open-cathode polymer electrolyte fuel cells : A combined ex- situ X-ray tomography and in-operando neutron imaging study, Electrochim. Acta 2016; 211:478-87.

[62] S. Chevalier, N. Ge, J. Lee, M.G. George, H. Liu, P. Shrestha, D. Muirhead, N. Lavielle, B.D. Hatton, A. Bazylak, Novel electrospun gas diffusion layers for polymer electrolyte membrane fuel 
cells : Part II . In operando synchrotron imaging for microscale liquid water transport characterization, J. Power Sources 2017; 352:281-90.

[63] A. Iranzo, P. Boillat, J. Biesdorf, E. Tapia, A. Salva, Liquid water preferential accumulation in channels of PEM fuel cells with multiple serpentine flow fields, Int. J. Hydrogen Energy 2014; 39(28):15687-95.

[64] S.S. Alrwashdeh, I. Manke, H. Markötter, J. Haußmann, N. Kardjilov, A. Hilger, M.J. Kermani, M. Klages, A.M. Al-Falahat, J. Scholta, J. Banhart, Neutron radiographic in operando investigation of water transport in polymer electrolyte membrane fuel cells with channel barriers, Energy Convers. Manag 2017; 148:604-10. 